\title{
ONE-DIMENSIONAL ANALYSIS OF LIQUEFACTION POTENTIAL: A CASE STUDY IN CHIANG RAI PROVINCE, NORTHERN THAILAND
}

\author{
Lindung Zalbuin MASE${ }^{1}$, Tetsuo TOBITA ${ }^{2}$ and Suched LIKITLERSUANG ${ }^{3}$ \\ ${ }^{1}$ Ph.D. Student, Dept. of Civil Eng., Faculty of Engineering, Chulalongkorn University \\ (254 Phayathai Rd, Pathumwan, Bangkok 10330, Thailand) \\ E-mail: lindung.za@student.chula.ac.th \\ ${ }^{2}$ Member of JSCE, Associate Professor, Dept. of Civil, Environmental, and Applied System Eng., Kansai University \\ (3-3-35 Yamate-cho, Suita, Osaka 564-8680, Japan) \\ E-mail: tobita@kansai-u.ac.jp \\ ${ }^{3}$ Professor, Dept. of Civil Eng., Faculty of Engineering, Chulalongkorn University \\ (254 Phayathai Rd, Pathumwan, Bangkok 10330, Thailand) \\ E-mail: fceslk@eng.chula.ac.th
}

\begin{abstract}
Liquefaction was investigated after the $6.8 \mathrm{M}_{\mathrm{w}}$ earthquake on March 24, 2011 (Tarlay earthquake) in Chiang Rai Province, Northern Thailand. Several investigations including soil boring, SPT, and SASW tests were carried out and the results were used to perform one dimensional wave propagation analysis using finite element method. The maximum acceleration of $0.206 \mathrm{~g}$ recorded in Chiang Rai was used as the input motion. The input motion was applied at bottom of soil column to observe soil behavior under seismic loading. The result shows that liquefaction could occur at shallow depth (0 to $16.5 \mathrm{~m})$, which is also followed by settlement (1.8 to $4 \mathrm{~cm}$ ) due to compressibility of soil during earthquake. The analysis result indicates that there is no significant dissipated pore water pressure on liquefied layer. The longer duration of liquefaction is identified on layer (SP-SM), which have the low SPT values. Excess pore water pressure from bottom layer might also concentrate at this layer. The concentration of excess pore water pressure may trigger the duration of liquefaction up to 50 seconds. In addition, the excess pore water pressure ratio linked to impacted depth warns that the soils with excess pore water pressure in range of 0.9 to 1 are possible to get worse impact if a stronger earthquake attacks this area in the future.
\end{abstract}

Keywords: liquefaction potential, finite element, wave propagation analysis, Tarlay earthquake

\section{INTRODUCTION}

On $24^{\text {th }}$ of March 2011, the $6.8 \mathrm{M}_{\mathrm{w}}$ earthquake triggered by Nam-Ma Fault (Fig. 1) hit the border of Thailand-Myanmar. The epicenter of this earthquake was reported at Tarlay (i.e. $20.705^{\circ} \mathrm{N}, 99.949^{\circ} \mathrm{E}$ ), Myanmar, with focal depth of $10 \mathrm{~km}$. The location of epicenter was about $30 \mathrm{~km}$ from the northern border of Thailand-Myanmar.

Northern Thailand was one of the affected areas because of Tarlay Earthquake. Much destruction was found in this area, especially in Chiang Rai, the closest Thailand Province to the earthquake epicenter. The maximum PGA (peak ground acceleration) of earthquake recorded at Mae Sai Station (in Chiang Rai Province) was $0.206 \mathrm{~g}$. The large earthquake energy resulted in the destructive damage and the other hazard, such as liquefaction. Learning from this event, several liquefaction studies in Thailand have been conducted.

Several researchers reported and studied liquefaction event because of Tarlay earthquake. Ruangrassamee et al. ${ }^{1)}$ reported liquefaction event because of the earthquake. Based on the report, sand layer with loose to medium density were liquefied during the 2011 earthquake. These sand layers are present at the top layers in Chiang Rai and Chiang Mai Provinces. Soralump and Feugaugsorn ${ }^{2)}$ reported that Mae Sai District was the vulnerable area of liquefaction because of Tarlay earthquake. As Ruangrassamee et al. result, loose and medium dense sand at depth 3.5 to $11 \mathrm{~m}$ might be liquefied in this area. They also stated that the liquefaction on this area was the first eyewitness in Thailand during modern times of Thailand ${ }^{2)}$, especially in the last century. Further, Tanapalungkorn and Teachavorasinskun ${ }^{3)}$ studied 
the susceptibility of liquefaction in Northern Thailand by considering Tarlay earthquake as well. In their study, they also confirmed that Northern Part of Thailand, especially Chiang Rai was vulnerable to undergo liquefaction. Mase et al. ${ }^{4)}$ reviewed the previous studies of liquefaction in Northern Thailand because of Tarlay earthquake. They conducted the conventional analysis to estimate liquefaction severity in the Chiang Rai area. They confirmed that liquefaction might potentially occur at shallow depth.

In general, the previous studies were conducted by using simplified analysis to predict safety factor and critical depth. However, the detail study in term of soil behavior under Tarlay earthquake shaking is still rarely conducted.

In this study, the one-dimensional analysis is performed to find out the soil behavior during an earthquake. This study is expected to figure out a better understanding of liquefaction and to confirm the previous studies of liquefaction conducted in Northern Thailand.

\section{METHOD}

\section{(1) Research area and geologic condition}

This study is focused on Chiang Rai Province that underwent the serious impact because of liquefaction on March 24, 2011. Three sites are studied here (Fig. 1). They are CR-1 (Wiang Pa Pao District), CR-2 (Muang District), and CR-3 (Mae Sai District).

The soil investigation test results conducted in Chiang Rai are presented in Fig. 2. In general, sandy soils, including SP (poorly graded sand), SM (silty sand), and SC (clayey sand) are dominant in Chiang Rai. Fines content (FC) of these sandy soils ranged from 7 to $26 \%$. Thin clay layer was also found on some boreholes (CR-1 at depth 0 to $2.5 \mathrm{~m}$ and CR-2 at depth 29.5 to $30 \mathrm{~m}$ ). The groundwater was generally found at shallow depth. In term of soil resistance, the value of $\left(N_{1}\right)_{60}$ in this area ranged from 3 to 25 blows $/ 30 \mathrm{~cm}$, whereas the range of $V_{S 30}$ was 285 $\mathrm{m} / \mathrm{s}$ to $319 \mathrm{~m} / \mathrm{s}$. According to NEHRPcriteria ${ }^{5}$, the general site class of Chiang Rai was categorized as Site Class Type D (stiff soil).

\section{(2) Ground motion}

To model seismic loading under Tarlay Earthquake load, a ground motion record was applied at each base of the site investigation point. In this study, ground motion recorded at Mae Sai Station (the closest station to the epicenter) was used (Thai Meteorological Department (TMD) in 2015 $5^{6}$ ). Fig. 3 presents the acceleration time history of Mae Sai ground motion.

\section{(3) Finite element approach for seismic response analysis}

In this study, the effective stress analysis based on by Elgamal et al. ${ }^{7}$ model is performed to observe soil behavior under earthquake. In the model, soil nonlinearity simulated by the incremental plasticity is performed to model deformation and damping. The finite element approach in both dry and saturated strata used the coupled solid-fluid approach. Therefore, this method may generate and dissipate excess pore water pressure. Besides, this approach may explore the important information related to seismic response of soil and soil behavior under dynamic load. The brief explanation about constitutive modeling and theory of this approach is discussed here.

The cyclic stress-strain behavior in saturated sandy soil is complex ${ }^{8)}$. However, there is any exception for loose sands at low confining pressure, which behave as contractive material marking generation of positive pore water pressure. To get the better understanding, Ishihara et al. ${ }^{9)}$ introduced phase transformation (PT) to describe the behavior of saturated sandy soil under dynamic load.

The general trend of cyclic effective stress path and shear-strain curves to explain Ishihara et al. ${ }^{9)}$ explanation is presented in Fig. 4. Once the shear stress ratio has been reached, there is a transformation phase from contraction to dilation. This condition happens when the effective stress path achieves phase transformation line (phase 1). The soil stiffness increment and effective stress path movement (phase 2) also happen. Once the reverse load is applied, the effective confining pressure reduction happens. Besides, soil will behave as contractive material (phase 3 to phase 4) and be followed by the accumulation of excess pore water pressure at phase 5 . Furthermore, it may fail at phase 6 . The reverse of compression to extension will reach the transformation line at phase 7. It will continuously result in shear strain and excess pore water pressure accumulations (phase 8). Similar to compression, it may fail at phase 9 .

Many constitutive models were developed to describe cyclic behavior of sand. One of them is finite element effective stress proposed by Elgamal et al. ${ }^{7)}$. The model was developed based on Parra ${ }^{11)}$ and Yang ${ }^{12)}$. This model also adopted the framework of multi-yield surface plasticity proposed by Prevost ${ }^{13)}$ ).

In this model, the importance is placed on controlling the permanent shear strain accumulation in sand types ${ }^{11,12)}$. The phases in Fig. 4 are incorporated by developing the new flow rule in this model. The incorporated new flow rule may significantly change the characteristic of model response. The incorporated new flow rule may also reproduce cyclic mobility mechanisms (Fig. 4). The incorporated flow 
rule also exercises more direct control over shear strain accumulation ${ }^{10)}$. In addition, a new kinematic hardening rule was developed (Fig. 5) into multi-yield surface. The stiffness is evaluated in each incremental step. In calculation, excess pore water pressure and pore water pressure dissipation are modeled under cyclic loading. The detail can be found on Elgamal et al. ${ }^{14)}$, Yang and Elgamal ${ }^{15)}$, Elgamal et al. ${ }^{10)}$, Yang et al. ${ }^{16)}$ and Yang et al. ${ }^{17)}$.

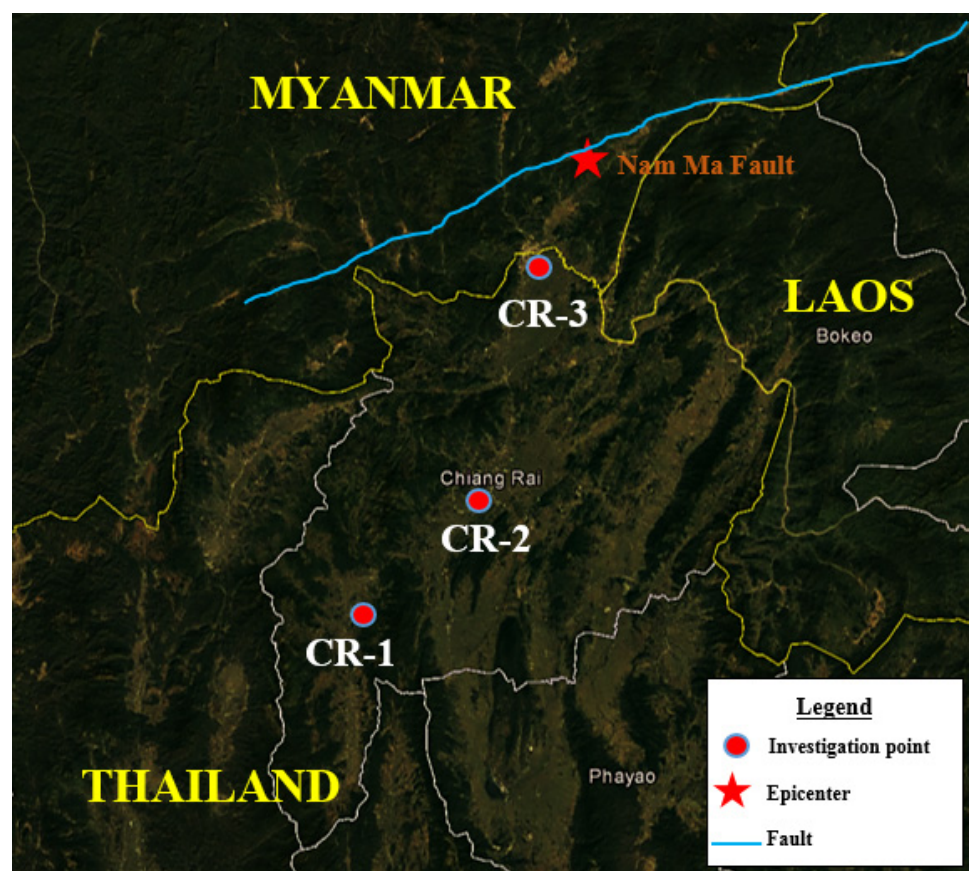

Fig. 1 Location of site investigation points conducted in this study and the epicenter location of $6.8 \mathrm{M}_{\mathrm{w}}$ on March 24, 2011 in Tarlay.
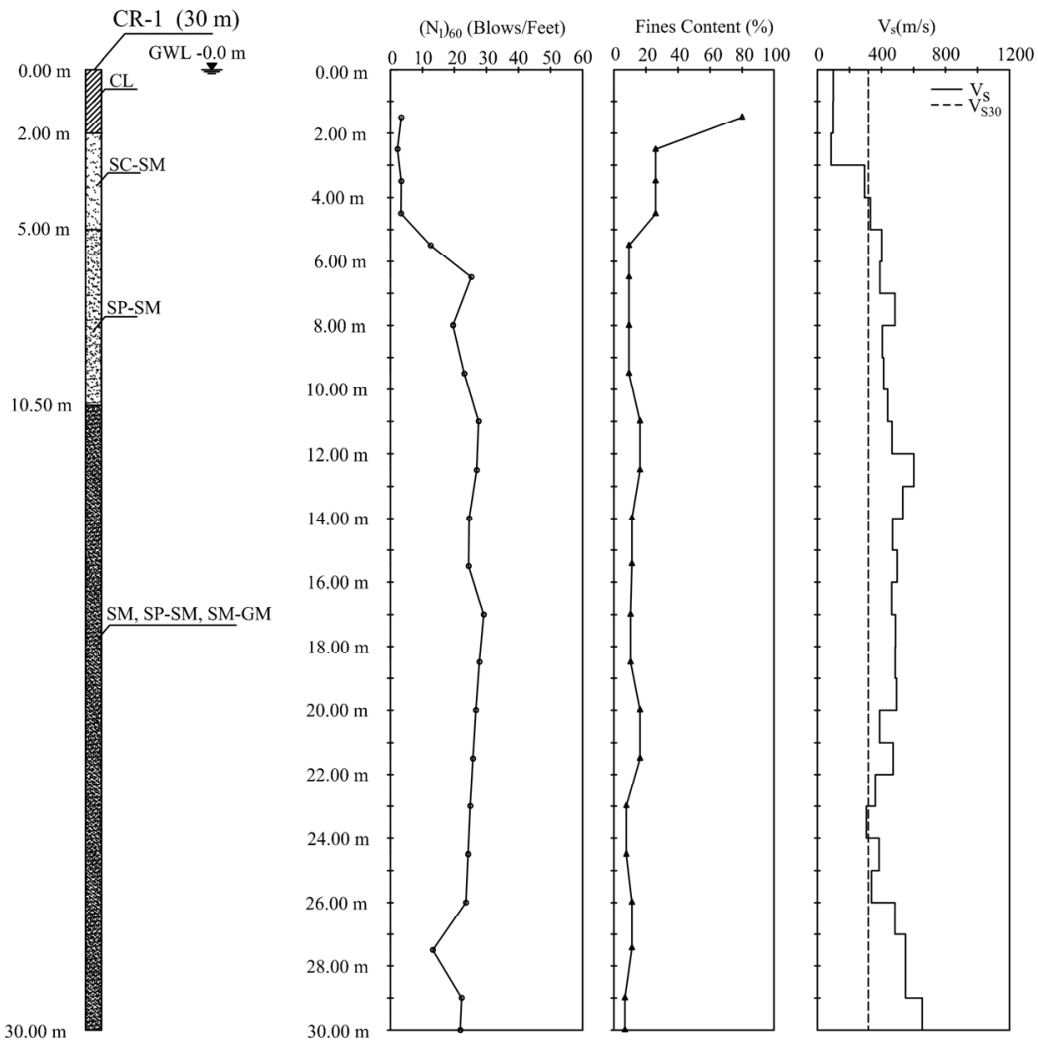

(a)

Fig. 2 Site investigation conducted in Chiang Rai Province (a) CR-1, (b) CR-2, and (c) CR-3. 
A1 (Structural Engineering \& Earthquake Engineering (SE/EE)), Vol. 73, No. 4, I_135-I_147, 2017.
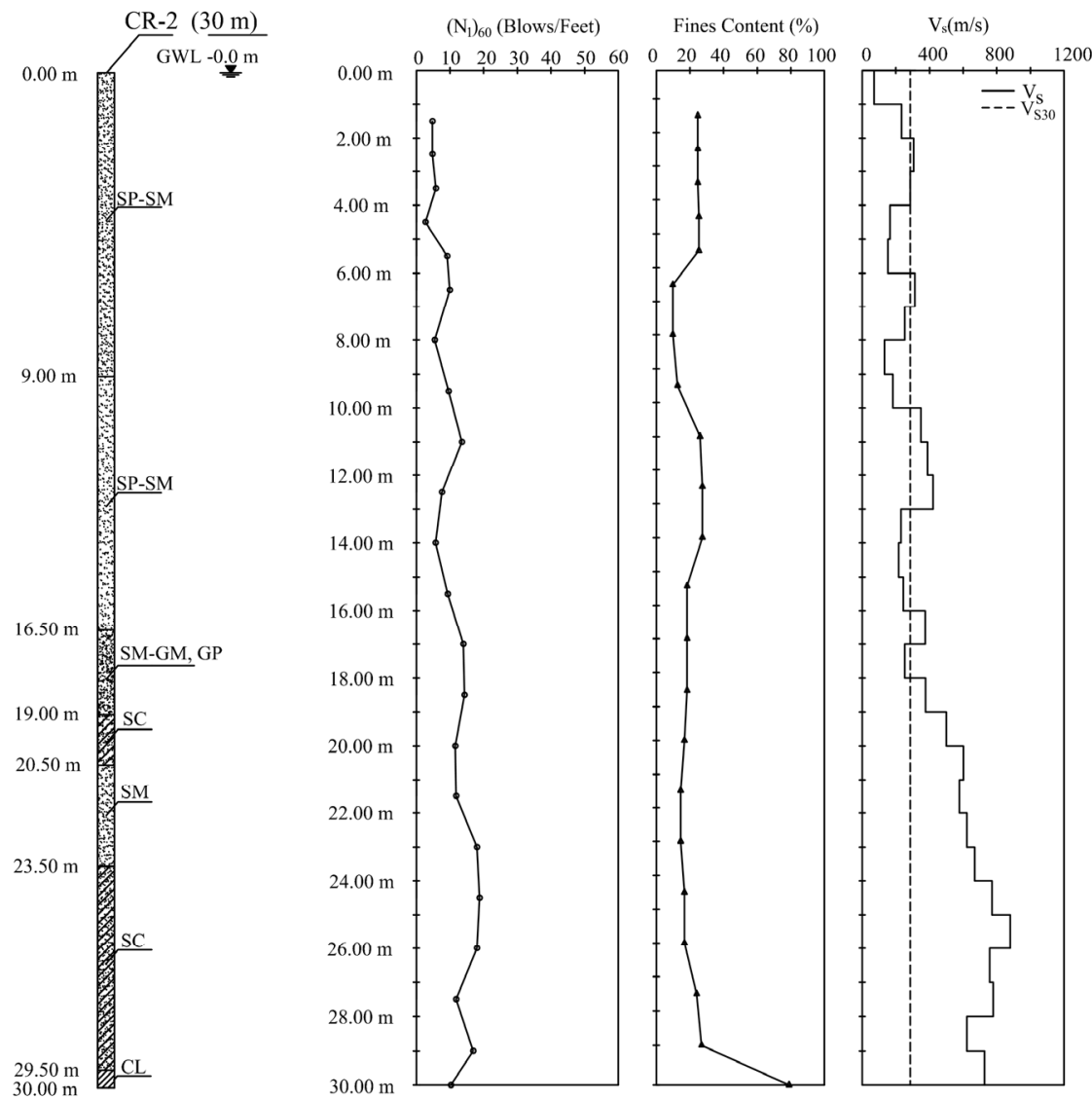

(b)
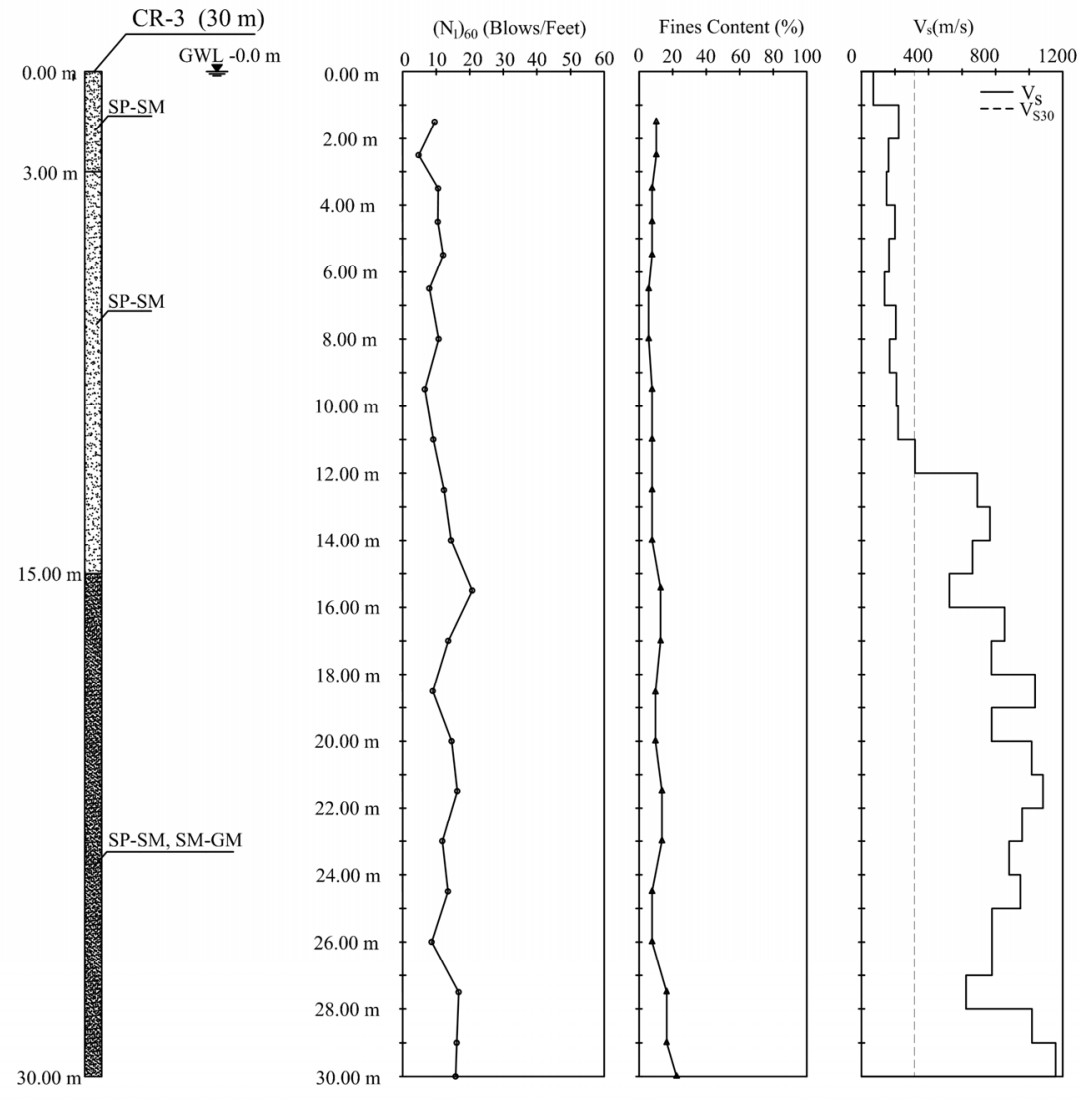

(c)

Fig. 2 (continued) Site investigation conducted in Chiang Rai Province (a) CR-1, (b) CR-2, and (c) CR-3 


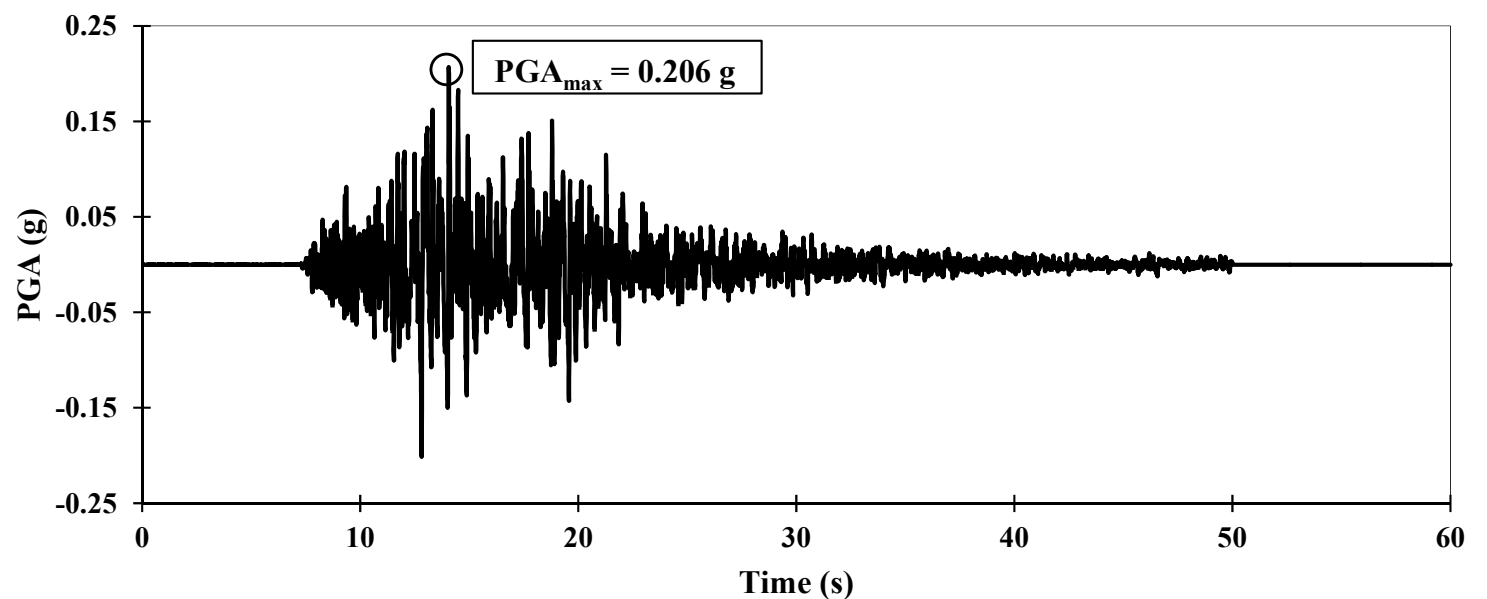

Fig. 3 Acceleration record of Mae Sai Station during the $6.8 \mathrm{M}_{\mathrm{w}}$ earthquake on 24 March $2011^{6}$.

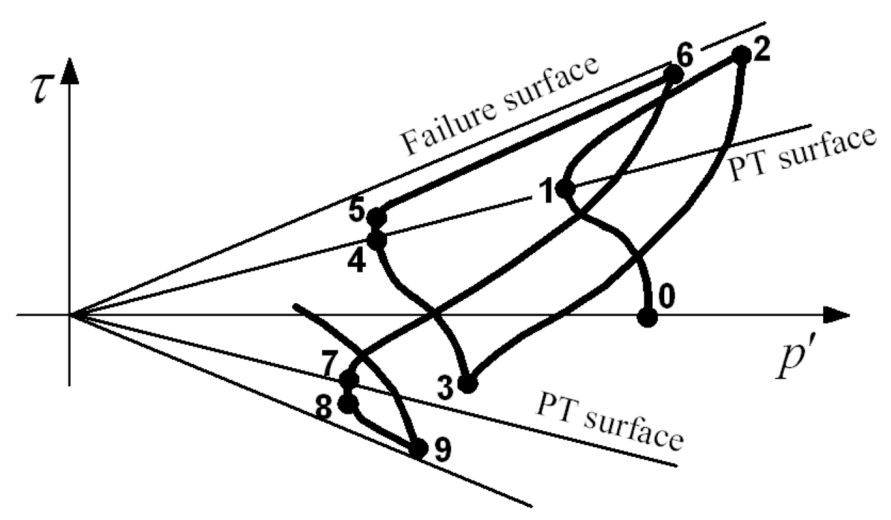

(a)

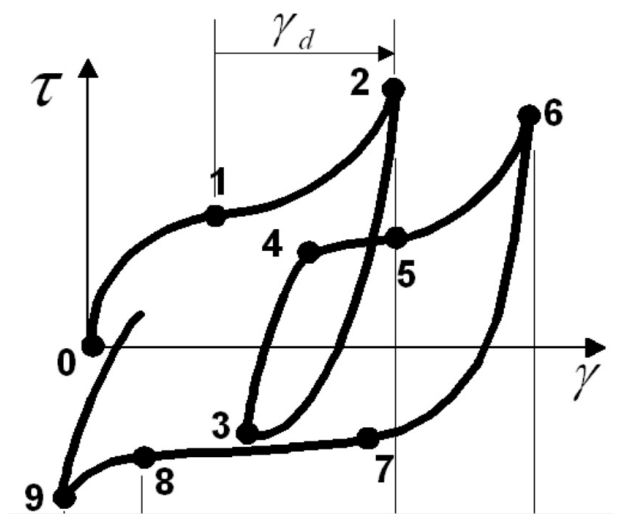

(b)

Fig. 4 Soil behavior under dynamic load (a) Effective stress path of shear strain model for sand under cyclic mobility ${ }^{10)}$ (b) Mean principal effective stress; $\tau$, shear stress; $\gamma$, shear strain, and PT, phase transformation locus of sand under cyclic mobility ${ }^{10)}$.

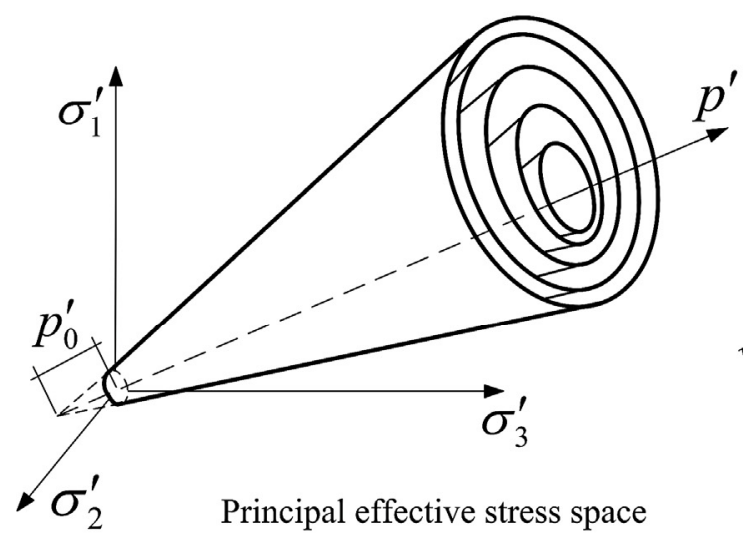

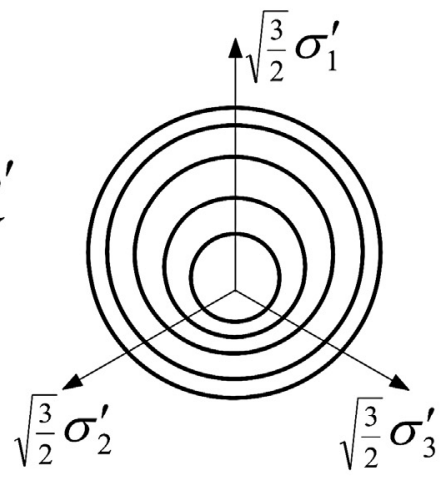

Deviatoric plane

Fig. 5 Multi-yield surface of kinematic hardening yield locus in principal stress and deviatoric plane (after Prevost ${ }^{13)}$, Parra ${ }^{11)}$ and Yang ${ }^{12)}$.

\section{(4) Modeling criteria}

In this study, one-dimensional analysis is performed to the soil column. The soil column is assumed to be fully saturated. It is taken to consider the worst condition of the soil column. The effective stress is estimated based on water table depth and soil density. The lateral effective stress is estimated based on the effective stress and the coefficient of lateral earth pressure at rest $\left(K_{o}\right)$. Further, excess pore water pressure ratio $\left(r_{u}\right)$ is calculated by effective stress and excess pore water pressure. Liquefaction occurs when $r_{u} \geq 1$. In this study, liquefaction simulation is performed by applying the input motion at soil column bottom. Figure 6 draws the soil column model and loading in this study. In Fig. 6, the boundary condition is limited only on vertical direction of soil column. However, displacement in both vertical and horizontal directions could happen dur- 
ing wave propagation. Once the wave is propagated from the base of soil column, pore water pressure will build up in vertical direction. It is because there is no drainage path on lateral direction. The boundary condition at the bottom is assumed as the fixed boundary. The bottom boundary is assumed as the impermeable layer (there is no drainage path). Since there is no available information of seismic bedrock ( $V_{S}$ range of 3000 to $5000 \mathrm{~m} / \mathrm{s}$ ), so that the shallower interface of which underlying stratum having $V_{S} \geq$ $760 \mathrm{~m} / \mathrm{s}$ is used as the engineering bedrock for the simulation. Considering the limitation of the data and based on site investigation results, the depth of $30 \mathrm{~m}$ can be assumed as the surface of engineering bedrock. Therefore, on each borehole, the input motion is applied at that depth. Mesh size of the soil column model is $0.5 \mathrm{~m}$. The detail explanation of mesh calculation is also presented in Fig. 6.

The Material properties (Table 1) of each layer are determined based on either undisturbed or disturbed sampling test from the soil sample taken from boring test. The brief explanations of material properties are presented below,

- $\quad \gamma$ is density of soil

- $F C$ is fines content of soil

- $\quad c$ is cohesion of soil

- $\phi$ is internal friction angle of soil

- $k$ is permeability coefficient of soil
- $V_{\text {Saverage }}$ is average shear wave velocity for the soil layer

- $K_{o}$ is coefficient of lateral earth pressure at rest

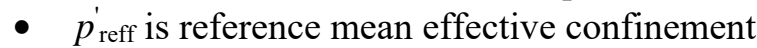

- $\gamma_{\max }$ is peak shear strain

- Liq is liquefaction parameters, which dictates the extent of shear strain accumulation (e.g. phases 4-5 and 7-8 (Fig. 4)). Recommended range of values is $0.025-0.00$ (for very loose to very dense sands)

- $\quad c_{1}$ and $c_{2}$ are the contraction parameters. $c_{1}$ dictates the rate of pore pressure build up under undrained condition. Recommended range of values is 0.3 to 0.0 (for very loose to very dense sands). $\quad c_{2}$ reflects the effect of overburden pressure on contraction behavior. Recommended range of values is 0.2 to 0.6 (for very loose to very dense sands)

- $\quad d_{1}$ and $d_{2}$ are the dilation parameters. $d_{1}$ reflects the rate of volume expansion or reduction of pore pressure. Recommended range of values is 0.0 to 0.6 (very loose to very dense sands). $d_{1}$ dictates the effect of accumulated shear strain on dilation parameter. Recommended value is 10 .

For details, the complete guideline how to define the properties was presented in Elgamal et al. ${ }^{7)}$.

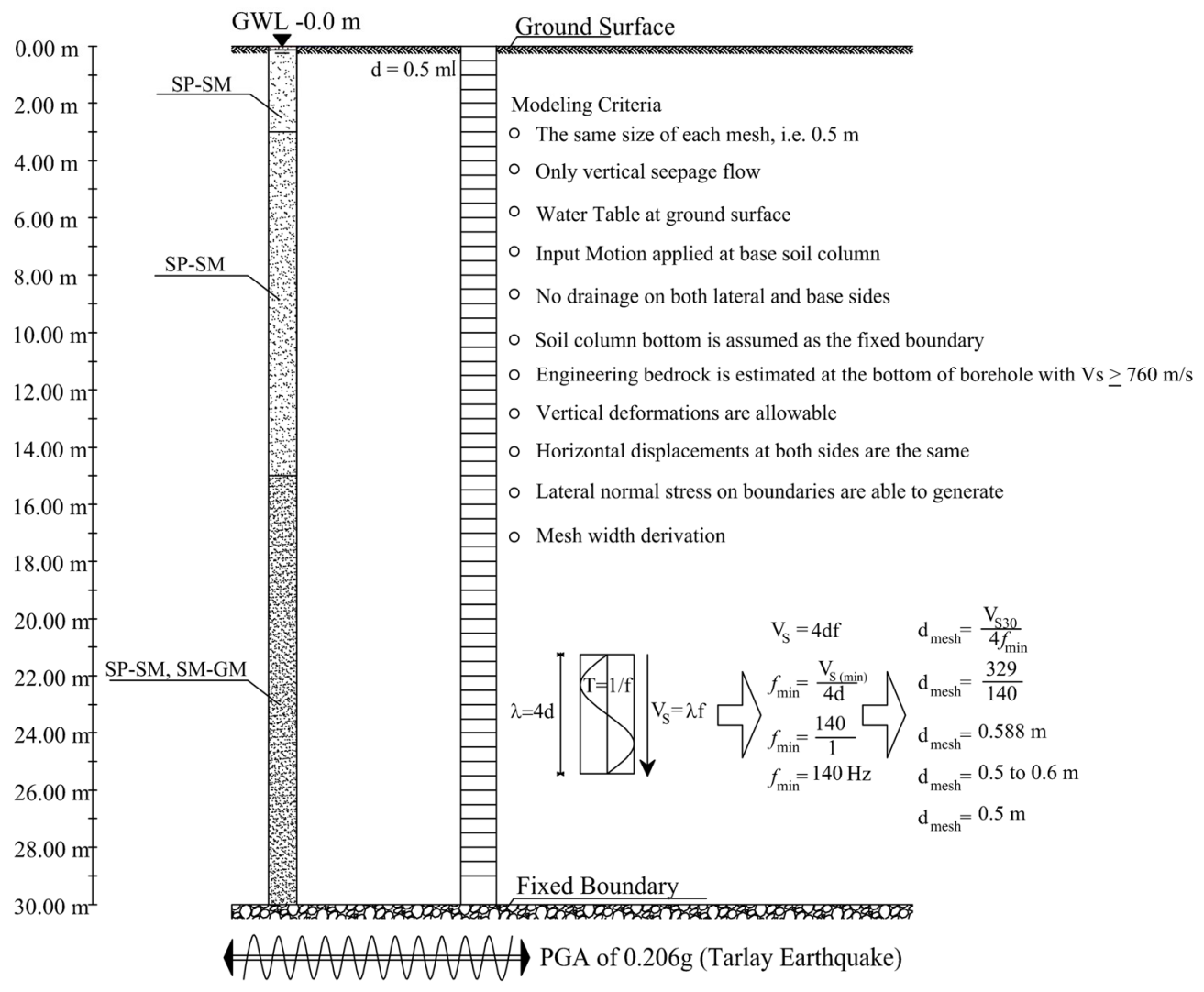

Fig. 6 Modeling criteria in this study. 
Table 1 Input material in this study.

\begin{tabular}{|c|c|c|c|c|c|c|c|c|c|c|c|c|c|c|c|c|}
\hline \multirow{2}{*}{ BH } & \multirow{2}{*}{ Material } & Thickness & $\gamma$ & $c$ & $\phi$ & $F C$ & $k$ & $V_{s(\text { ave })}$ & $K_{o}$ & $p_{\text {ref }}^{\prime}$ & $\gamma_{\max }$ & Liq & $c_{1}$ & $c_{2}$ & $d_{1}$ & $d_{2}$ \\
\hline & & (m) & $\left(\mathrm{kN} / \mathrm{m}^{3}\right)$ & $(\mathrm{kPa})$ & $\left({ }^{\circ}\right)$ & $(\%)$ & $(\mathrm{m} / \mathrm{s})$ & $(\mathrm{m} / \mathrm{s})$ & $(-)$ & $(\mathrm{kPa})$ & $(\%)$ & $(-)$ & $(-)$ & $(-)$ & $(-)$ & $(-)$ \\
\hline \multirow{4}{*}{ CR-1 } & $\mathrm{CL}$ & 2.0 & 1.3 & 18 & - & 80 & $1.1 \times 10^{-9}$ & 99 & 0.67 & 50 & 5 & - & - & - & - & - \\
\hline & SP-SM & 3.0 & 1.7 & 0.3 & 28 & 8 & $6.6 \times 10^{-5}$ & 237 & 0.53 & 80 & 5 & 0.025 & 0.30 & 0.2 & 0.0 & 10 \\
\hline & SP-SM & 5.5 & 2.0 & 0.3 & 29 & 8 & $6.6 \times 10^{-5}$ & 421 & 0.52 & 80 & 5 & 0.010 & 0.06 & 0.5 & 0.4 & 10 \\
\hline & SM, SP-SM, SM-GM & 19.5 & 2.1 & 0.3 & 30 & 11 & $6.6 \times 10^{-5}$ & 472 & 0.50 & 80 & 5 & 0.003 & 0.01 & 0.6 & 0.6 & 10 \\
\hline \multirow{7}{*}{ CR-2 } & SP-SM & 9.0 & 1.7 & 0.3 & 0 & 21 & $6.6 \times 10^{-5}$ & 195 & 1.00 & 80 & 5 & 0.025 & 0.30 & 0.2 & 0.0 & 10 \\
\hline & SP-SM & 7.5 & 1.7 & 0.3 & 29 & 26 & $6.6 \times 10^{-5}$ & 259 & 0.52 & 80 & 5 & 0.025 & 0.30 & 0.2 & 0.0 & 10 \\
\hline & SM-GM,GP & 2.5 & 2.0 & 0.3 & 9 & 19 & $6.6 \times 10^{-5}$ & 266 & 0.84 & 80 & 5 & 0.010 & 0.06 & 0.5 & 0.4 & 10 \\
\hline & $\mathrm{SC}$ & 1.5 & 2.0 & 3 & 29 & 18 & $6.7 \times 10^{-5}$ & 273 & 0.52 & 80 & 5 & 0.010 & 0.06 & 0.5 & 0.4 & 10 \\
\hline & SM & 3.0 & 2.0 & 0.5 & 19 & 16 & $6.9 \times 10^{-5}$ & 600 & 0.67 & 80 & 5 & 0.010 & 0.06 & 0.5 & 0.4 & 10 \\
\hline & $\mathrm{SC}$ & 6.0 & 2.0 & 3 & 30 & 21 & $7.1 \times 10^{-5}$ & 634 & 0.50 & 80 & 5 & 0.010 & 0.06 & 0.5 & 0.4 & 10 \\
\hline & $\mathrm{CL}$ & 0.5 & 1.4 & 20 & - & 94 & $1.1 \times 10^{-9}$ & 728 & 0.68 & 50 & 5 & - & - & - & - & - \\
\hline \multirow{3}{*}{ CR-3 } & SP-SM & 3.0 & 1.7 & 0.3 & 28 & 7 & $6.6 \times 10^{-5}$ & 140 & 0.53 & 80 & 5 & 0.025 & 0.30 & 0.2 & 0.0 & 10 \\
\hline & SP-S & 12.0 & 2.0 & 0.32 & 29 & 9 & $6.9 \times 10^{-5}$ & 324 & 0.52 & 80 & 5 & 0.010 & 0.06 & 0.5 & 0.4 & 10 \\
\hline & SP-SM,SM-GM & 15.0 & 2.1 & 0.25 & 30 & 9 & $7.0 \times 10^{-5}$ & 736 & 0.50 & 80 & 5 & 0.003 & 0.01 & 0.6 & 0.6 & 10 \\
\hline \multicolumn{7}{|c|}{$\begin{array}{l}\text { Note } \\
\text { - } \gamma \text { and } F C \text { is saturated soil density and fines content, respectively } \\
\text { - } c \text { and } \phi \text { are soil cohesion and internal friction angle, respectively } \\
\text { - } k \text { is permeability coefficient } \\
\text { - } V_{\text {s(ave) }} \text { is the average shear wave velocity of soil layer } \\
\text { - } K_{o} \text { is lateral earth pressure at rest }\end{array}$} & $\begin{array}{l}\text { - } \gamma_{\max } \\
\text { - Liq } \\
\text { - } c_{1} \text { an } \\
\text { - } d_{1} \text { ar }\end{array}$ & $\begin{array}{l}\text { s lique } \\
\text { d } c_{2} \text { ar } \\
\text { ad } d_{2} d\end{array}$ & $\begin{array}{l}\text { tact } \\
\text { e co } \\
\text { ilati }\end{array}$ & tiv & & & & & & \\
\hline
\end{tabular}

\section{(5) Element simulation}

To obtain the appropriate information in terms of liquefaction behavior, the element simulation is conducted. Furthermore, the result obtained from the element simulation is compared with the liquefaction resistance curve, which was obtained from laboratory testing with the typical liquefaction criterion of $5 \%$ double amplitude axial strain. The comparison between the computed result and the liquefaction resistance curve is presented in Fig. 7. Generally, based on the simulation, not all soil layers are categorized as liquefiable layers. In CR-1, the potentially liquefiable layers include Sand Layer 1 (SC-SM) and CR-2(SP-SM). In CR-2, the sand layers 1 and 2 dominated by SP-SM are liquefiable layers. Similar to CR-2, in CR3, the sand layers 1 and 2 (SP-SM) are also categorized as the liquefiable layer. The simulation results also deal with the liquefaction re- sistance curve. Furthermore, the computed results also show that all simulated elements can be liquefied within 20 cyclic and reach liquefaction condition before completing the targeted points. Based on the element simulation result, we can also presume that the SP-SM layer may potentially undergo liquefaction.

\section{RESULT AND DISCUSSION}

\section{(1) Pore water pressure and settlement after liq- uefaction}

Figure 8 depicts pore water pressure and settlement after liquefaction to analyzed depth. In this study, since there is no the information for the actual settlement due to liquefaction, so only the analyzed settlement from simulation is presented.

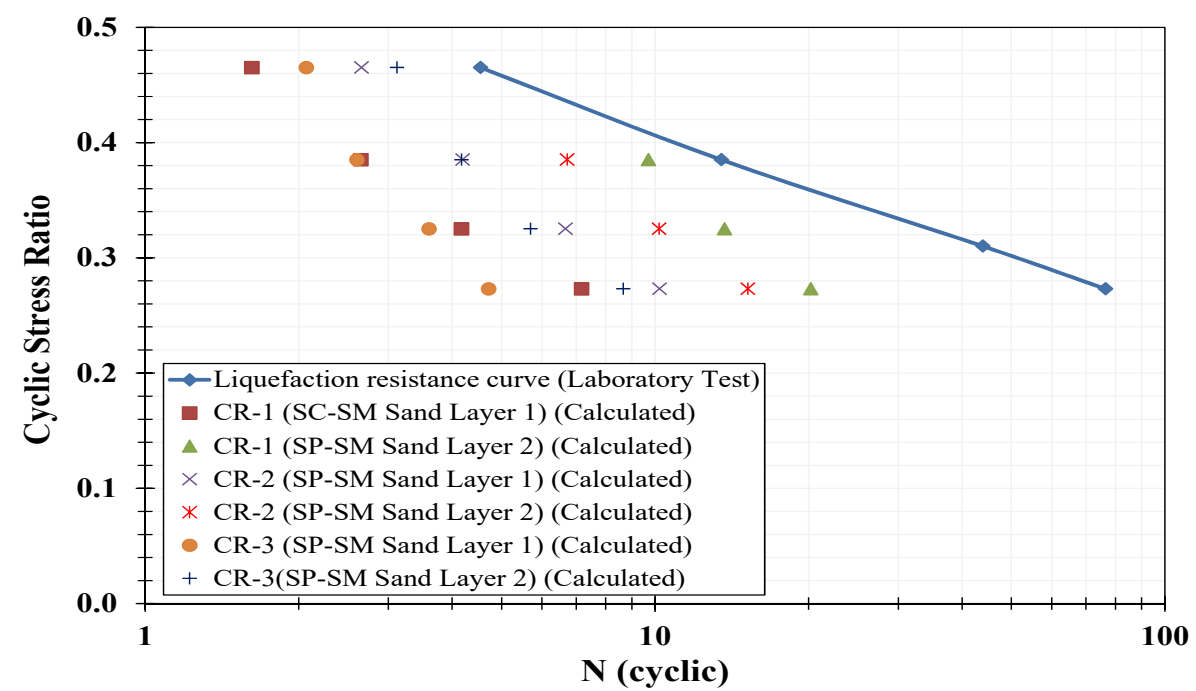

Fig. 7 Liquefaction resistance curve comparison for all liquefiable layers from element simulations. 
In $\mathrm{CR}-1$, the excess pore water pressure results in liquefaction from 2 to $5 \mathrm{~m}$ deep or second layer (Fig. 8a). At this depth, the excess pore water pressure ratio $\left(r_{u}\right)$ resulted ranges from 0.998 to 1.13 . At the depth of 0 to 2 ( $1^{\text {st }}$ layer $), 5$ to $10.5 \mathrm{~m}$ ( $3^{\text {rd }}$ layer $)$, and 10.5 to $30 \mathrm{~m}$ (fourth layer) excess pore water pressure may not trigger liquefaction. $10 \mathrm{~s}$ after the completion of the excitation, the dissipated excess pore water pressure is also observed. In general, there exists drained pore water pressure, especially in the liquefiable layer ( 2 to $5 \mathrm{~m}$ deep). The residual excess pore water pressure seems to be concentrated at this depth. At $3^{\text {rd }}$ and $4^{\text {th }}$ layers, pore water pressure dissipation is also very limited. Liquefaction also resulted in the ground settlement. Settlement up to 1.8 $\mathrm{cm}$ occurred at ground surface. It is caused by the compressed sandy layer at 2 to $5 \mathrm{~m}$ deep. For depth of 5 to $30 \mathrm{~m}$ deep, the settlement is small.

For CR-2 (Fig. 8b), liquefaction possibly occurs at the depth of 0 to $16.5 \mathrm{~m}$ deep $\left(1^{\text {st }}\right.$ and $2^{\text {nd }}$ layers $)$. It is confirmed by the excess pore water pressure exceeding the initial effective stress on these layers. On these layers, the calculated $r_{u}$ ranges from 0.971 to 1.06. For layers underneath liquefiable layers, excess pore water pressure is not large enough to trigger liquefaction. The excess pore water pressure ratio of those layers is in the range of 0.1 to 0.5 . In general, there is no significant dissipated pore water pressure on each depth, except at 4 to $9 \mathrm{~m}$. In terms of settlement due to compression of liquefiable soil, the settlement at ground surface reaches to $4.15 \mathrm{~cm}$. For the depth of 16.5 to $30 \mathrm{~m}$, the settlement is small.

Liquefaction on shallow depth is also found on CR-3 (Fig. 8c). Liquefaction possibly occurs at depth of 0 to $15 \mathrm{~m} \mathrm{(} 1^{\text {st }}$ and $2^{\text {nd }}$ layers $)$, which are dominated by SP-SM in layer 1 and layer 2. The excess pore water pressure ratio in this range is 0.990 to 1.020 . Similar to both previous sites, liquefaction is also not found in the deeper depth (from 15 to $30 \mathrm{~m}$ deep or third layer). In this range, the excess pore water pressure ratio is about 0.402 to 0.913 . Besides, after the excitation, the dissipated pore water pressure is found on $9.5 \mathrm{~m}$ to $21 \mathrm{~m}$ deep. For depth of 0 to $9.5 \mathrm{~m}$ and depth of 21 to $30 \mathrm{~m}$, pore water pressure is not well dissipated. In CR-3, the settlement at the ground surface is observed at $3.15 \mathrm{~m}$ deep. Obviously, settlement is observed at ground surface to $15.5 \mathrm{~m}$ deep. Meanwhile, at depth of 15.5 to $30 \mathrm{~m}$, settlement is very small. In general, CR-1 has the lowest potential to undergo liquefaction. CR-1 has the susceptible layer about $3 \mathrm{~m}$ and the impacted of settlement of 1.8 $\mathrm{cm}$. Meanwhile, CR-2 (the total liquefied depth of $16.5 \mathrm{~m}$ ) is more susceptible than CR-3 (the total liquefied depth of $15 \mathrm{~m}$ ). For other sites, settlement of CR-2 is larger than CR-3, i.e. $4.15 \mathrm{~cm}$ and $3.15 \mathrm{~cm}$ at the ground surface, respectively.

\section{(2) Soil layer behavior under wave propagation}

Figure 9 to 13 present soil behavior in liquefied layers (at mid-thickness) of soil columns. For CR-1 (Fig. 9), at $2.5 \mathrm{~m}$ deep, excess pore water pressure has exceeded the initial effective stress at $9^{\text {th }}$ sec. It remains constant and exceeds the initial effective stress up to 1-minute. After excitation, pore pressure seems not easily drained. At this depth, the shear stress-shear strain curve (hysteresis loop) becomes unstable, which shows the irregular shape of the curve. As observed, the curve tends to become progressively flatter because the soil element starts to liquefy and after the completion of liquefaction, the curve is almost horizontal. It indicates that there is a reduction of shear modulus during the cyclic mobility. The cyclic mobility also resulted in the reduction of effective confining pressure, which is confirmed by the reduction of effective confinement pressure to zero. This marks that soil layer loses the shear stress because of effective stress reduced by the excess pore water pressure.

In CR-2, liquefaction also occurs at shallow depth, i.e. from 0 to $16.5 \mathrm{~m}$ deep. This result has been confirmed by soil behavior interpretation on each mid depth of soil layers. At depth of $4.5 \mathrm{~m}$ (Fig. 10), the initial effective stress has been passed by the excess pore water pressure in a short time i.e. $12^{\text {th }}$ seconds. At depth of $13 \mathrm{~m}$ (Fig. 11), the same phenomenon is also clearly observed. The hysteresis loops also show the similar trend with the CR-1 hysteresis loop, which shows the soil element behavior under liquefaction. It indicates that there is the reduction of effective confining due to the excess pore water, which resulted in the loss of shear stress.

Similar to both previous sites, liquefaction in CR-3 is also predicted to occur at shallow depth. Liquefiable layers are represented on $1.5 \mathrm{~m}$ deep (Fig. 12) and $9 \mathrm{~m}$ deep (Fig. 13). At both points, excess pore water pressure has exceeded the initial effective stress in short time, i.e. $9^{\text {th }}$ and $13^{\text {th }}$ sec, respectively. At these points, the shear stress-shear strain curves also tend to become unstable due the cyclic mobility. The curves go to flat in the beginning time of liquefaction and are almost horizontal after liquefaction. In addition, the cyclic mobility also drops the effective confining pressure to be zero. It explains there is the significant excess pore water pressure triggering loss of shear stress at both layers. 

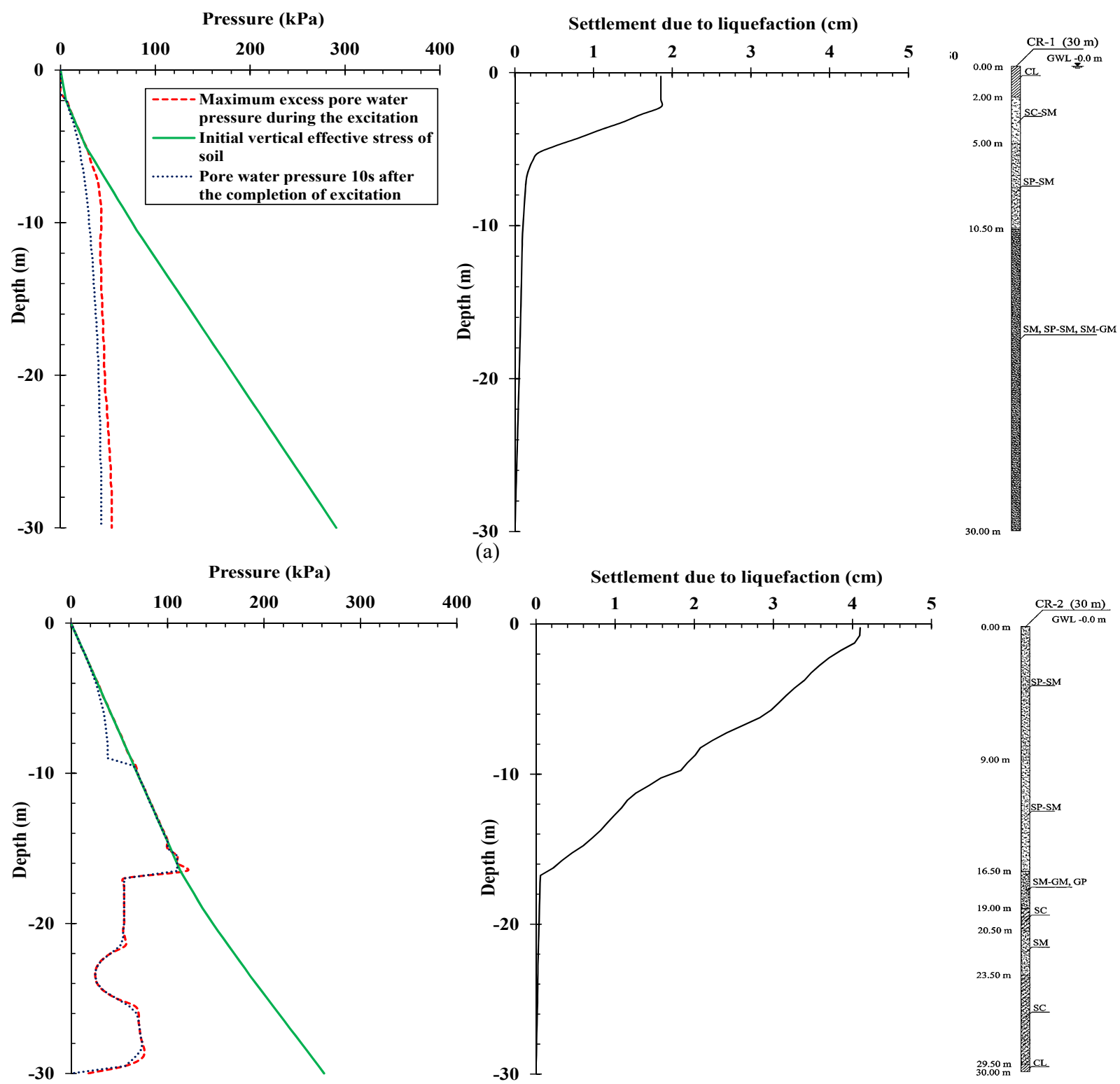

(a)

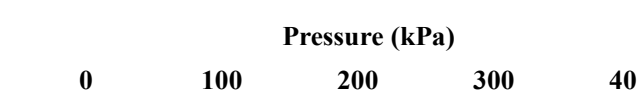

(b)
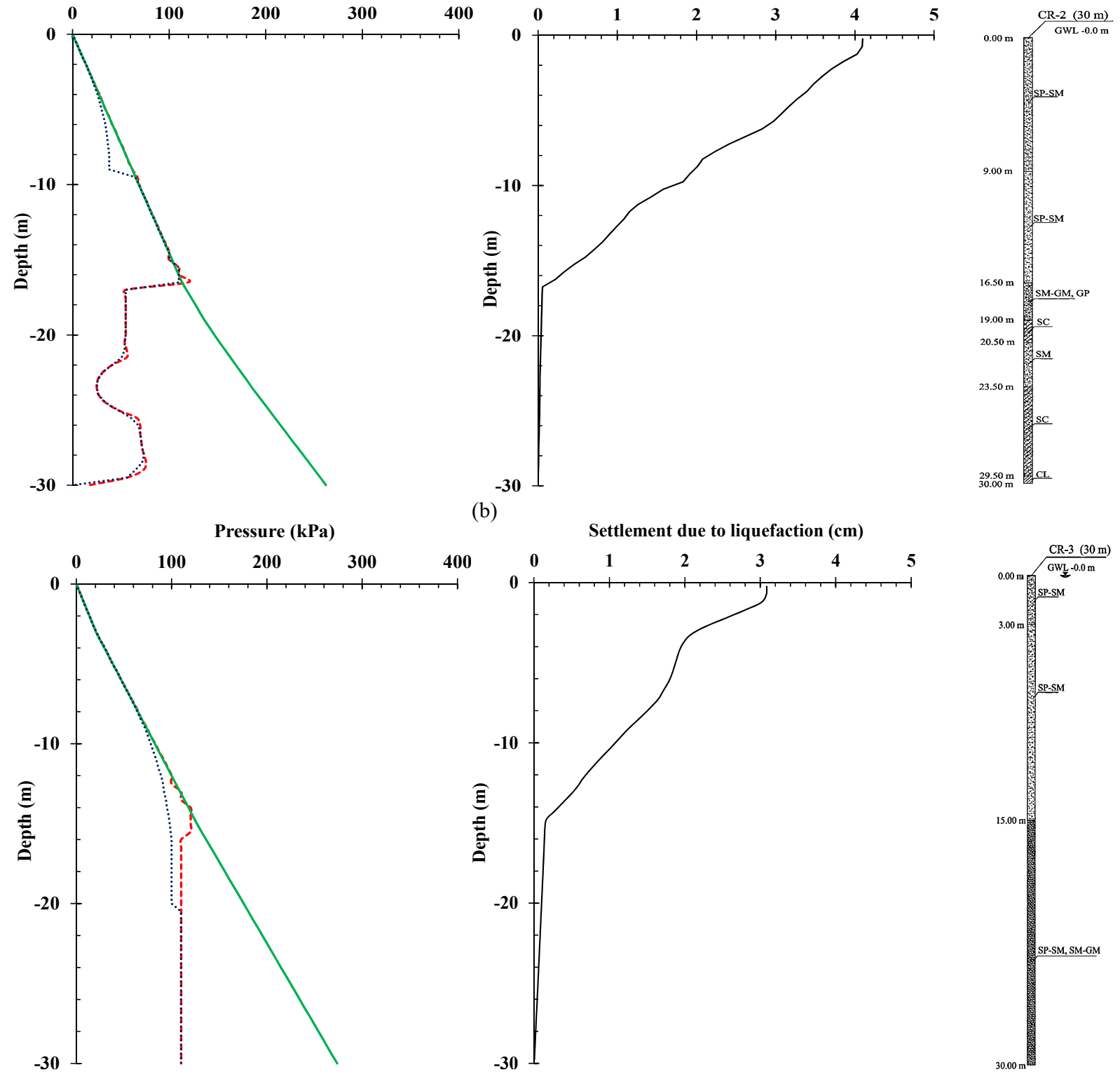

Fig. 8 Pore water pressure and settlement due to liquefaction on each depth (a) CR-1 (b) CR-2 (c) CR-3. 


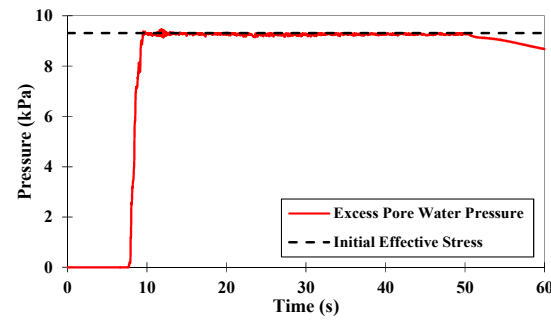

(a)

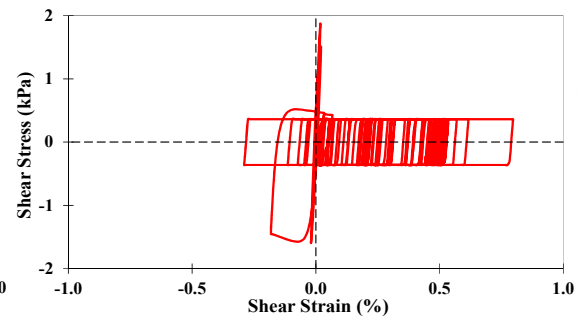

(b)

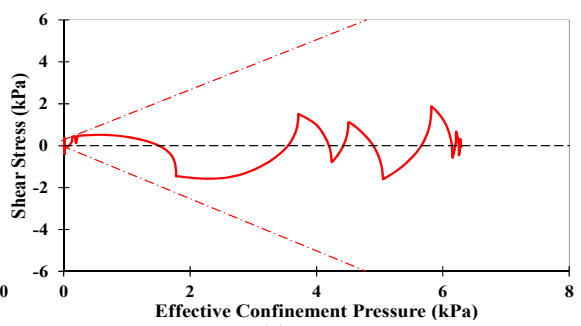

(c)

Fig. 9 Soil behavior of CR-1 (at $2.5 \mathrm{~m}$ ) (a) Pore pressure (b) shear strain-shear stress (c) effective confinement pressure-shear stress.

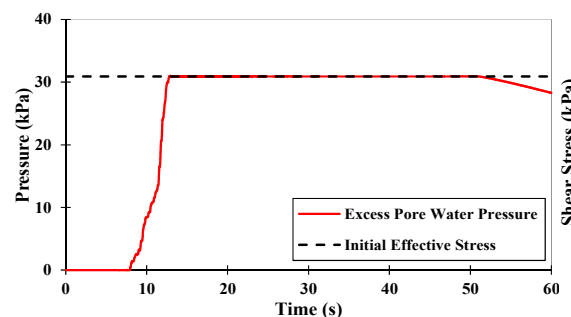

(a)

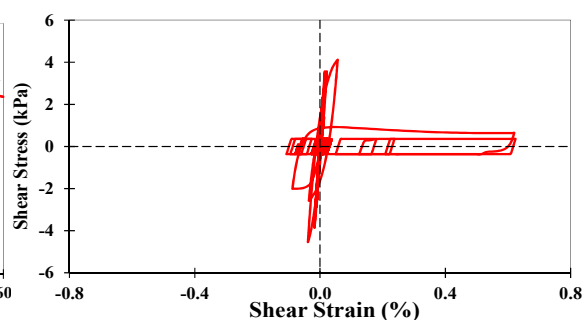

(b)

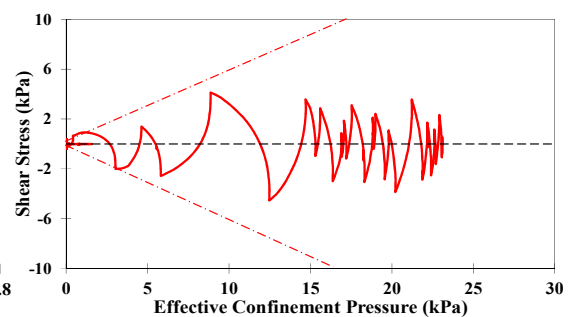

(c)

Fig. 10 Soil behavior of CR-2 (at $4.5 \mathrm{~m}$ ) (a) Pore pressure (b) shear strain-shear stress (c) effective confinement pressure-shear stress.

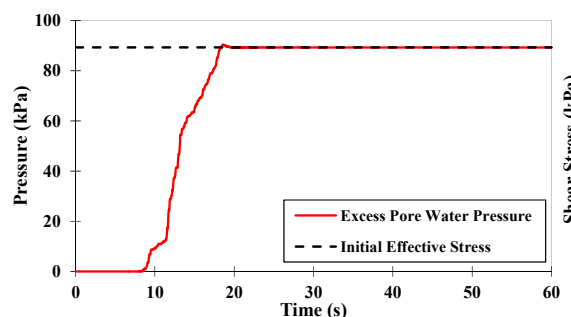

(a)

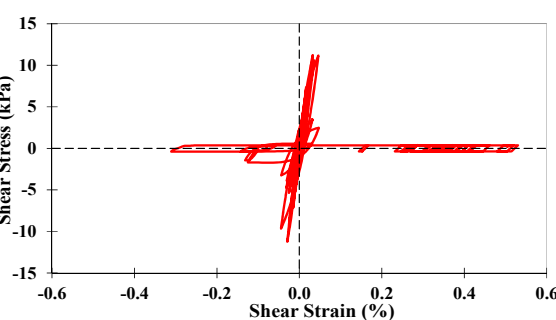

(b)

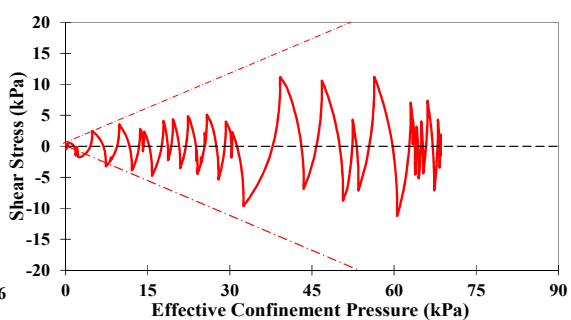

(c)

Fig. 11 Soil behavior of CR-2 (at 13 m) (a) Pore pressure (b) shear strain-shear stress (c) effective confinement pressure-shear stress.

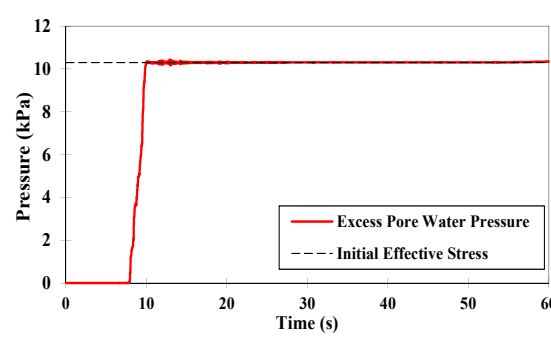

(a)

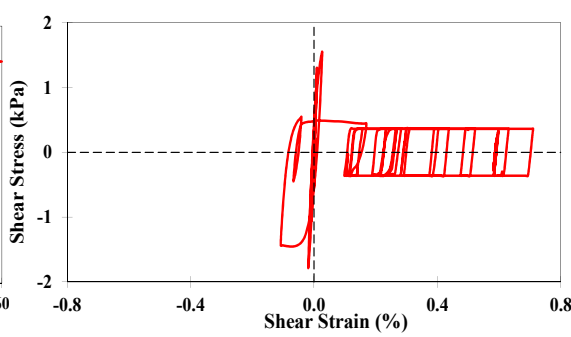

(b)

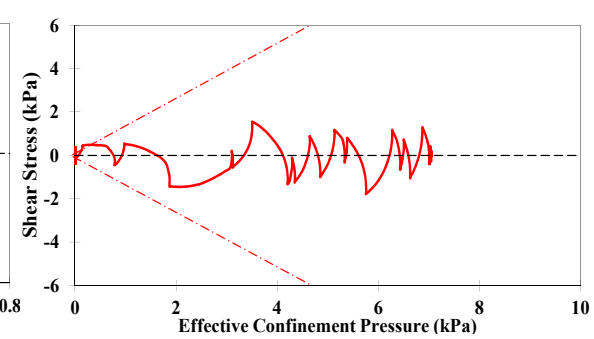

(c)

Fig. 12 Soil behavior of CR-3 (at $1.5 \mathrm{~m}$ ) (a) Pore pressure (b) shear strain-shear stress (c) effective confinement pressure-shear stress.

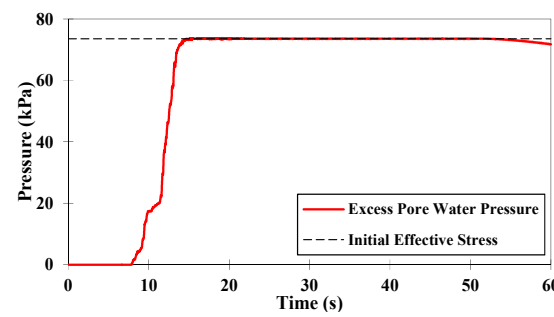

(a)

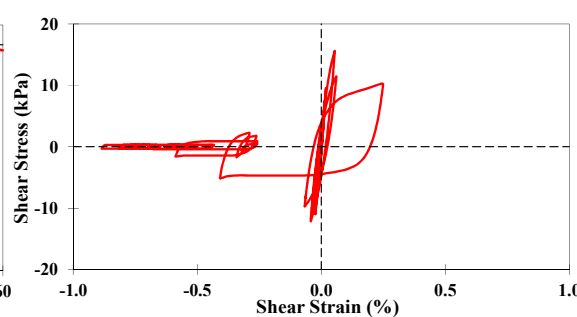

(b)

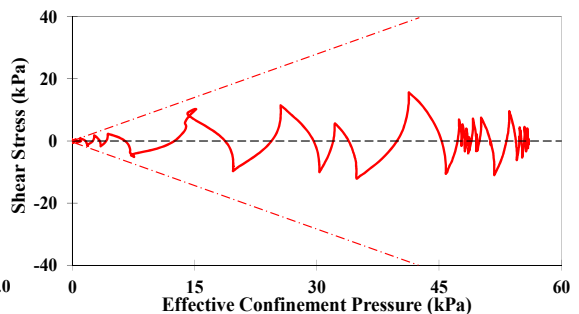

(c)

Fig. 13 Soil behavior of CR-3 (at 9 m) (a) Pore pressure (b) shear strain-shear stress (c) effective confinement pressure-shear stress.

\section{(3) Excess pore water pressure ratio}

Figure 14 shows both maximum and minimum excess pore water pressure ratios in liquefiable layers on both during and $10 \mathrm{~s}$ after the completion of the excitation. In general, maximum excess pore water pressure on both during and $10 \mathrm{~s}$ after the completion of excitation did not show significant gap. It means that after completion the excitation, maximum excess pore water pressure still concentrates at peak value. In other word, excess pore water pressure dissipation is small. For minimum excess pore water pressure, there is any difference between excess pore water pressure ratio during excitation and $10 \mathrm{~s}$ after the completion of the excitation. It suggests that excess pore water pressure undergoes the dissipation. In general, maximum excess pore water pressure ratio 
of liquefiable layer (Fig. 14a) is generated at depth near ground surface. Minimum excess pore water pressure ratio of liquefiable layer (Fig. 14b) is generated at deeper depth to the ground surface. For example, maximum excess pore water pressure ratio in CR-1 is found on $2 \mathrm{~m}$ deep, whereas minimum one is found on $5 \mathrm{~m}$ deep. It is influenced by excess pore water pressure and effective stress values. Excess pore water pressure building up gives the contribution to decrease the initial effective stress. At shallow depth, due to the bottom-up pressure of excess pore water, the propagated energy transfers the pore water pressure from a deeper depth to a shallower depth to drain at the free surface. Moreover, excess pore water pressure accumulates and concentrated on shallow depth. The accumulation obviously decreases the effective vertical stress at a shallower depth, which is smaller than at a deeper depth. Therefore, near the ground surface, the excess pore water pressure ratio is larger than deeper depth.

\section{(4) Liquefaction duration}

The duration of liquefaction is calculated based on the time history of excess pore water pressure. Table 2 presents the duration of liquefaction for the soil layers. The duration of liquefaction is obtained from the difference between the time taken to build up liquefaction (initial time of liquefaction) and the finished time of liquefaction. In general, CR-3 has the longest duration $(50 \mathrm{sec})$, i.e. at Layer 1. The shortest duration $(39 \mathrm{sec})$ is provided by Layer 1 of CR-2 and Layer 3 of CR-3. The duration is obviously influenced by excess pore water pressure. In Chiang Rai site, the liquefiable soils are dominated by sandy layer with soil type of SP-SM. This soil type (SP-SM) has lower resistance of SPT than SC, GM, and GP. The lower resistance usually provides lower shear stress and tends to be more contractive. Once the excess pore water pressure builds up, and exceeds the initial effective stress, it will be concentrated at a liquefied point during excitation. Even shortly after excitation, the remained energy of wave propagation still contributes to keep the excess pore water pressure concentrating at threshold point $\left(r_{u} \approx 1\right)$.

\section{(5) Percentage of total $r_{u}$ max on overall sand layers and impacted depth}

Table 3 presents the percentage of excess pore water pressure ratio resulted in all sand layers. In Table 3, excess pore water pressure ratio is divided into 7 groups. Table 3 is linked to Table 4, which shows the impacted depth. Percentage of $r_{u}$ max on overall sand layers is defined as the percentage of the $r_{u \max }$ identified on overall sand layer element in one dimensional analysis. For example, in CR-1, the total element of $r_{u \max }$ equal or more than 1 is 5 elements and the total of sand layer elements is 57 . Then the percentage of $r_{u \max } \geq 1$ is counted as $(5 / 57) * 100 \%$. Therefore, the percentage of percentage of $r_{u \max } \geq 1$ is $8.77 \%$.

Based on the percentage of total $r_{u \max }$, the total impacted depth corresponding to the $r_{u \max }$ can be determined. For example, from the previous explanation, the percentage of $r_{u \max } \geq 1$ is $8.77 \%$ and the total sand depths of sand layers in CR-1 is $29 \mathrm{~m}$. Next, the total impacted depth can be determined by $0.877 * 29$. Therefore, the total impacted depth for $r_{u \max } \geq 1$ is $2.34 \mathrm{~m}$.

In Table 3, CR-3 and CR-2 undergo worse impacted depth than CR-1. It is seen from the percentage of $r_{u \max } \geq 1$ on both investigated points are larger than CR-1. It indicates that the impacted depth in CR-1 $(2.54 \mathrm{~m})$ is thinner than CR-2 $(11.31 \mathrm{~m})$ and CR-2 $(9.84 \mathrm{~m})$. From the results, the critical depths $r_{u \max } \geq 1$ in CR-2 and CR-3 are generally larger than CR-1. The critical depth of the Chiang Rai Site is identified from 2.5 to $11.3 \mathrm{~m}$ deep. It is very critical for shallow foundation or medium length pile. We also need to concern to the depth with $r_{u}$ of 0.9 to 1 . If an earthquake with the bigger magnitude and PGA attacks this depth range in the future, the generated excess pore water pressure ratio on these depths might become higher. If this condition is completed, the impacted depth will become larger.

\section{CONCLUSIONS}

This study focuses on an analysis of soil liquefaction during 24 March 2011 earthquake or Tarlay earthquake. We conducted several analyses, such as seismic response analysis, excess pore water pressure analysis, and soil behaviour under existing earthquake loading.

During Tarlay earthquake, Northern Thailand experienced liquefaction. Liquefaction during Tarlay earthquake was found in shallow depth, as reported in several previous studies. In this study, the result also shows liquefaction at shallow depth. It is indicated by excess pore water pressure ratio more than or equal to one. Also, the liquefaction results in settlement, which is predicted about 1.8 to $4 \mathrm{~cm}$ at ground surface. It shows there is compressibility on liquefiable layer because of input motion. However, to conduct the detail analysis during an earthquake, the physical model, such as $1 \mathrm{~g}$ model or scaled model (centrifuge test) test should be conducted.

Maximum and minimum excess pore water pressure ratios during and after an earthquake are also observed. The result shows the excess pore water pressure ratio is not easily drained. It is confirmed by 
similar excess pore water pressure ratios on both during and after earthquakes. The result shows minimum excess pore water pressure ratio is generated at depth having larger effective stress. Otherwise, maximum excess pore water pressure ratio is generated at depth with smaller effective stress. The result also indicates that the bottom-up pressure of excess pore water gave the contribution to keep the pore water pressure concentrating at shallow depth. In addition, the effect of vibration after the completion of the excitation still produces a small amount of pore water pressure. This continuous effect seems also to contribute to decreasing effective stress at shallow depth. Therefore, the excess pore water pressure ratio keeps higher during and after an earthquake. In the next study, excess pore water pressure and dissipated pore water pressure in long-term will be conducted to observe final pore water pressure distribution. It is also interesting to conduct the effect of aftershock to the reproduced excess pore water pressure.

The result shows that for SP-SM layer with a lower SPT value undergoes the longer liquefaction duration. The existence of soil resistance and bottom-up pressure of pore water pressure play role in liquefaction duration. In general, the impacted depth is identified at shallow depth. This gives the prediction due to the earthquake shaking impact in Northern Thailand. We also concern to the possibility of a stronger future earthquake. According to excess pore pressure ratio interpretation, the excess pore water pressure close to one is also found in the depth below the impacted depth. This depth is very vulnerable to liquefy when the stronger earthquake happens. Therefore, soil improvement for the shallow depth and specific foundation design on liquefiable layer should be concerned in Northern Thailand.

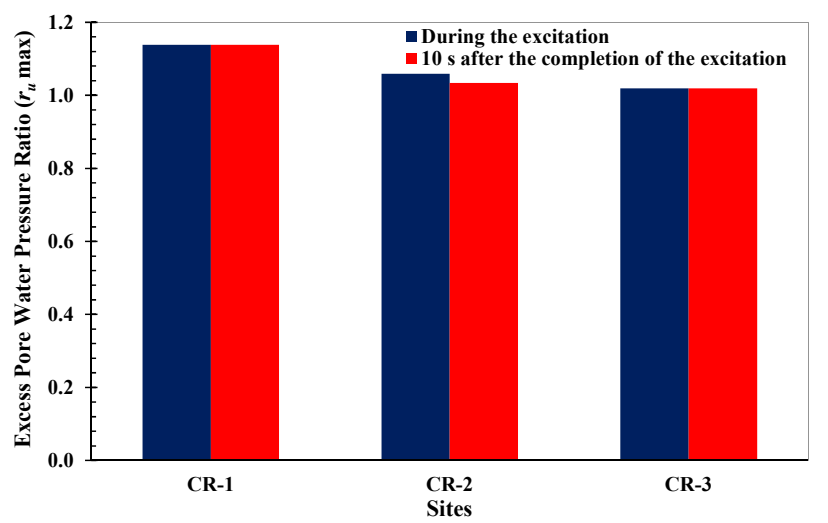

(a)

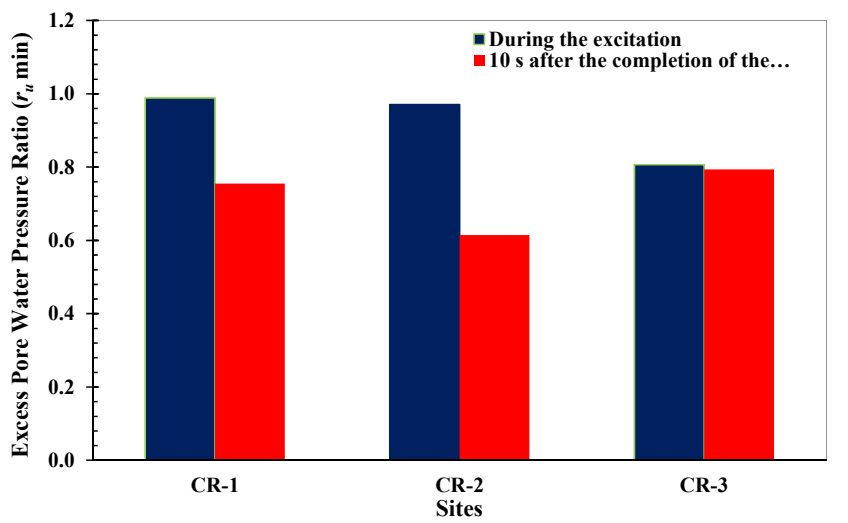

(b)

Fig. 14 Excess pore water pressure ratio during the excitation and 10 after the completion of the excitation (a) maximum value (b) minimum value/

Table 2 Liquefaction duration on soil layers (red colors are the liquefiable layers).

\begin{tabular}{lcccc}
\hline CR-1 & \multicolumn{5}{c}{ Tayers } & Soil Type & $\begin{array}{c}\text { Time taken in build-up } \\
\text { liquefaction (sec) }\end{array}$ & $\begin{array}{c}\text { Finished time of } \\
\text { liquefaction (sec) }\end{array}$ & $\begin{array}{c}\text { Duration of } \\
\text { liquefaction (sec) }\end{array}$ \\
\hline Layer 1 & CL & 0 & 0 & 0 \\
Layer 2 & SC-SM & $\mathbf{1 0}$ & $\mathbf{5 0}$ & 40 \\
Layer 3 & SP-SM & 0 & 0 & 0 \\
Layer 4 & SM, SP-SM, SM-GM & 0 & 0 & 0 \\
\hline CR-2 & & & & 39 \\
\hline Layer 1 & SP-SM & $\mathbf{1 3}$ & $\mathbf{5 2}$ & $\mathbf{6 3}$ \\
Layer 2 & SP-SM & $\mathbf{1 7}$ & 0 & 0 \\
Layer 3 & SM-GM,GP & 0 & 0 & 0 \\
Layer 4 & SC & 0 & 0 & 0 \\
Layer 5 & SM & 0 & 0 & 0 \\
Layer 6 & SC & 0 & 0 & 0 \\
Layer 7 & CL & 0 & & $\mathbf{5 0}$ \\
\hline CR-3 & & & $\mathbf{6 0}$ & $\mathbf{3 9}$ \\
\hline Layer 1 & SP-SM & $\mathbf{1 0}$ & 0 & 0 \\
Layer 2 & SP-SM & $\mathbf{1 5}$ & & \\
Layer 3 & SP-SM, SM-GM & 0 & &
\end{tabular}


Table 3 Percentage of $r_{u}$ in sand layer.

\begin{tabular}{|c|c|c|c|}
\hline \multirow{2}{*}{$\boldsymbol{r}_{\boldsymbol{u}}$ criteria } & \multicolumn{3}{|c|}{ Percentage of $\boldsymbol{r}_{\boldsymbol{u}}$ in overall sand layer (\%) } \\
\cline { 2 - 4 } & $\mathbf{C R - 1}$ & $\mathbf{C R - 2}$ & $\mathbf{C R - 3}$ \\
\hline$r_{u} \geq 1$ & 8.77 & 38.33 & 32.79 \\
\hline $0.9<r_{u}<1$ & 5.26 & 18.33 & 19.67 \\
\hline $0.8<r_{u}<0.9$ & 5.26 & 0.00 & 1.64 \\
\hline $0.7<r_{u}<0.8$ & 3.51 & 0.00 & 6.56 \\
\hline $0.6<r_{u}<0.7$ & 5.26 & 0.00 & 8.20 \\
\hline $0.6<r_{u}<0.5$ & 3.51 & 0.00 & 13.11 \\
\hline$r_{u}<0.5$ & 68.42 & 43.33 & 18.03 \\
\hline
\end{tabular}

Table 4 Impacted depth based on $r_{u}$.

\begin{tabular}{|c|c|c|c|}
\hline \multirow{2}{*}{$\boldsymbol{r}_{u}$ criteria } & \multicolumn{3}{|c|}{ Total Impacted depth (m) } \\
\cline { 2 - 4 } & CR-1 & CR-2 & CR-3 \\
\hline$r_{u} \geq 1$ & 2.54 & 11.31 & 9.84 \\
\hline $0.9<r_{u}<1$ & 1.53 & 5.41 & 5.90 \\
\hline $0.8<r_{u}<0.9$ & 1.53 & 0.00 & 0.49 \\
\hline $0.7<r_{u}<0.8$ & 1.02 & 0.00 & 1.97 \\
\hline $0.6<r_{u}<0.7$ & 1.53 & 0.00 & 2.46 \\
\hline $0.6<r_{u}<0.5$ & 1.02 & 0.00 & 3.93 \\
\hline$r_{u}<0.5$ & 19.84 & 12.78 & 5.41 \\
\hline
\end{tabular}

ACKNOWLEDGMENT: The authors would like to thank Dr. Suttisak Soralump for providing relevant data and useful suggestions throughout the research. The first author would be grateful for a Ph.D. scholarship from the AUN/SEED-Net (JICA). The work was performed under the Japan-ASEAN Science and Technology Innovation Platform (JASTIP).

\section{REFERENCES}

1) Ruangrassamee A., Ornthammarat T. and Lukkunaprasit P.: Damage due to 24 March 2011 M6.8 Tarlay Earthquake in Northern Thailand, Proceeding of $15^{\text {th }}$ World Conference of Earthquake Engineering (WCEE), Lisboa, Portugal, 2012.

2) Soralump S. and Feungaugsorn J.: Probabilistic analysis of liquefaction potential, the first eyewitness case in Thailand, Proceeding of $18^{\text {th }}$ National Convention of Civil Engineering (NCCE), Chiang Mai, Thailand, 2013.

3) Tanapalungkorn W. and Teachavorasinskun S.: Liquefaction susceptibility due to earthquake in Northern Parts of Thailand, Proceeding of the $20^{\text {th }}$ National Convention of Civil Engineering (NCCE), Chonburi, Thailand, 2015.

4) Mase, L. Z., Likitlersuang, S., Soralump S. and Tobita T.: Empirical study of liquefaction potential in Chiang Rai Province in the North of Thailand, Proceeding of the $28^{\text {th }}$
KKHTCNN Symposium on Civil Engineering, Bangkok, Thailand, 2015.

5) National Earthquake Hazards Reduction Program (NEHRP): Recommended Provisions for Seismic Regulation for New Buildings and Other Structures, 1997 Edition, Part 1 - Provisions, Part 2 - Commentary, FEMA 302, 1998.

6) Thai Meteorological Department (TMD): Seismological Bureau (Earthquake Data of 2011 Earthquake), Thai Meteorological Department, 2015.

7) Elgamal A., Yang Z. and Lu J.: Cyclic 1D: A computer program of seismic ground response, Department of Structural Engineering, University of California, San Diego, La Jolla. California, USA Report No. SSRP-06/05, 2006.

8) Pender M.J., Orense R.P., Wotherspoon L.M. and Storie L.B.: Effect of permeability on cyclic generation and dissipation of pore pressure in saturated gravel layers, Géotechnique, Vol.66, No.4, pp.313-322, 2016. DOI: 10.1680/jgeot.SIP.15. P.024.

9) Ishihara K., Tatsuoka F., and Yasuda, S.: Undrained deformation and liquefaction of sand under cyclic stresses, Soils and Foundations, Vol.15, No.1, pp.29-44, 1975.

10) Elgamal A., Yang Z., Parra E. and Ragheb A.: Modeling of cyclic mobility in saturated cohesionless soils, Int. J. Plasticity, Vol.19, No.6, pp.883-905, 2003.

11) Parra E.: Numerical modeling of liquefaction and lateral ground deformation including cyclic mobility and dilation response in soil system, PhD Thesis, Department of Civil Engineering, Rensselaer Polytechnic Institute, Troy, New York, USA, 1996.

12) Yang $Z .:$ Numerical modeling of earthquake site response including dilation and liquefaction, $\mathrm{PhD}$ Dissertation, Department of Civil Engineering and Engineering Mechanics, Columbia University, New York, USA, 2000.

13) Prevost, J.H.: A simple plasticity theory for frictional cohesionless soils, Soil Dynamics and Earthquake Engineering, Vol. 4, No.1, pp.9-17, 1985.

14) Elgamal Z., Yang Z. and Parra E.: Computational modelling of cyclic mobility and post liquefaction site response, Soil Dynamics and Earthquake Engineering, Vol.22, No.4, pp. 259-271, 2002.

15) Yang Z. and Elgamal A.: Influence of permeability on liquefaction induces shear deformation, J. Engineering Mechanics, ASCE, Vol. 128, No. 7, pp. 720-729, 2002.

16) Yang Z., Elgamal A. and Parra J.: Computational model for cyclic mobility and associated shear deformation, J. Geotechnical and Environmental Engineering, ASCE, Vol. 129, No. 12, pp. 1119-1127, 2003.

17) Yang Z., Lu J. and Elgamal A.: A web-based platform for computer simulation of seismic ground response, Advances in Engineering Software, Vol. 35, No. 5, pp. 249-259, 2004.

(Received November 4, 2016) 